\title{
METHYLATION CONCEPTS OF HTLV-1 THROUGH EPIGENETIC MECHANISM- A SYNOPTIC REVIEW
}

\author{
Surya Venkatesh \\ M. Tech., Molecular Medicine \\ Amrita Centre for Nanoscience \&Molecular Medicine \\ Amrita Institute of Medical Sciences, Kerala, India \\ Vijay Singh Pal \\ M.Sc. Microbiology \\ Department of Microbiology \\ Kurukshetra University, Haryana, India \\ Sakshi Mathpal \\ M.Sc. Microbiology \\ Department of Microbiology \\ Kurukshetra University, Haryana, India
}

\begin{abstract}
Epigenetics, essentially, is the study of chemical reactions that influence gene expression at specific times and locations or shed light on how environmental interactions lead to a differential change in gene expression. Some of the epigenetic mechanisms like methylation might affect individual susceptibility to a range of diseases. Thus, these discoveries pave the way for exploring fundamental science research that has illuminated how does a gain or loss of epigenetic "methyl marks" affects not only disease development and progression, but also phenotypic expression. In the studies conducted in the last twenty years, it has been discovered that a number of signalling pathways associated with different cancers can be activated by proteins of viruses. Patients suffering from varied cancers were detected with Human Lymphoma Virus-1, a causative agent of T-cell Lymphoma and Adult T-cell Leukemia. Initiation and expansion of cancers usually pertain to several factors and causes starting with the actuation of the first genetic alteration in the cell during mitosis directing augmentation of several somatic mutations with specific times for each one.
\end{abstract}

Keywords-HTLV-1, T-cell leukaemia, epigenetics, methylation, novel therapies.

\author{
Smruti Rekha Mohanty \\ B.Sc. Biotechnology \\ Department of Biotechnology BJB Autonomous College \\ Odisha, India \\ Himani Sharma \\ B. Pharmacy \\ Poona College of Pharmacy \\ Bharati Vidyapeeth University Maharashtra, India
}

\author{
Nikita Yadav \\ B.Sc. Biotechnology \\ Department of Biotechnology BJB Autonomous College \\ Odisha, India \\ I. INTRODUCTION
}

Concept of Epigenetics

Epigenetic mechanisms refer to the differences in the instructions in our DNA which are transmissible from parent to offspring to use information from a gene to synthesize a functional gene product without modifying the primary DNA sequence (Waterland R.A et al). These mechanisms regulate gene expression patterns and are in turn regulated by a spate of proteins. General consequences of epigenetic modifications or epimutations include altered phenotype and varied human disorders. (Michael Inbar-Feigenberg et al) This inherited epigenetic control is installed at the earlier stages of embryonic life. This section discusses various genetic epimutations responsible for altering the epigenome and determining gene expression patterns.

Difference between Epigenetic Alterations and Conventional Genetic Aberrations

Epigenetic mechanisms are essentially related to variation in gene expression potential, that is, the varied use of genes when passed onto from one generation to another due to alterations in the epigenome. Conventional genetic aberrations, on the other hand, are the modifications in inheritable DNA sequence. Epigenetic alterations can be both due to genetic as well as environmental factors, for example, stress, whereas conventional genetic modifications are due to mutagenesis. Genetics focuses on the 


\section{International Journal of Engineering Applied Sciences and Technology, 2020 \\ Vol. 5, Issue 8, ISSN No. 2455-2143, Pages 186-197 \\ Published Online December 2020 in IJEAST (http://www.ijeast.com)}

functionality of genes, that is, changes caused by DNA sequences in the host. Epigenetics deals with the regulation of genes to achieve changes in the host cells.

\section{Concept of DNA Methylation}

This includes covalent attachment of a methyl $\left(-\mathrm{CH}_{3}\right)$ group to the 5' position of a nucleotide cytosine at $\mathrm{CpG}$ (Cytosine preceding Guanine) sites which are the main target areas for methylation. Methylated genes do not undergo transcription because of the blocking of transcription initiation complexes, inhibition of RNA polymerase, and activation of repressor complexes of transcription. (Karam F Soliman et al) The inability of the genes to undergo transcription leads to alterations in cell functions and morphology. DNA methyltransferases are responsible for methylation. (W. Reik, W. Dean et al.) After the establishment of silencing expression patterns, miRNAs (non-coding) lead to degradation of mRNA resulting in local silencing. This silencing is further solidified by methyl CpG-binding proteins that directly fit $\mathrm{CpGs}$ through Methyl-CpG Binding Domains (MBDs) (Karam F Soliman et al).

\section{Histone Modifications}

Post methylations of $\mathrm{CpG}$ sites, histone modifications are next in order. The N-terminal tail of histone octamer undergoes modifications more frequently termed as histone marks. Histone modifications include acetylation, ubiquitination, methylation, prolineisomerisation, phosphorylation, sumoylation, and biotinylation on amino acid residues namely tyrosine, lysine, arginine, and serine. When histone marks come together, histone code is formed which is solidified by proteins like nucleosomalremodellers, PHDs, etc. through disruption of DNA packaging or compression of nucleosomes that are close to $\mathrm{CpGs}$ that underwent methylation. (Karam F Soliman et al)

Histone modifications are of $\mathrm{H} 3$ and $\mathrm{H} 4$ types. The most prevalent and researched modifications of $\mathrm{H} 3$ and $\mathrm{H} 4$ types include hyperacetylation by HATs and deacetylation by HDACs. These modifications have been regularly observed in the initiation and advancement of the disease.

\section{Nucleosomal Positioning}

Nucleosomal positioning includes twisting and sliding of nucleosomes which further involves a) stability of components $\mathrm{H} 2 \mathrm{~A}$ and $\mathrm{H} 2 \mathrm{~B}$ of histone octamer b) H1-the histone linker's integrity and c) nucleosomalremodelling complexes. (Karam F Soliman et al)

The stability of the histone core is compromised by the exchange process with collapsible and highly acetylated dimer which leads to the commencement of the ejection of the nucleosome at non-methylated DNA sites. (Wyrick JJ,
Parra MA et al) H2B core is modified by ubiquitination, acetylation, and sumoylation.

Unstable histone octamer component variants, like H2A.Z, lie close to the targets where transcription initiates, where disruption of H1-the histone linker is observed. (Braunschweig $\mathrm{U}$ et al). ATPase-driven chromatin remodeling complexes are present in the proximity of unmethylated CPGs and are involved in gene expression. BRD-consistingproteins bind to lysine which had undergone acetylation and have an association with transcription promotion. (Sanchez R).

\section{Relevance of Methylation}

Methylation is the chemical modification in which DNA or histone tail is subjected to the addition of methyl group which can have either an activating or repressing effect.HAT or histone acetyl transferase interact with the acetylated lysine in the core histone tails through bromodomains(acetyl lysine binding domain).Heterochromatin have conserved regions called chromodomains using HMTase (hetero methyltransferase) whose human form is known as SUV39H HMTase and HP1. When the methylation occur at the lysine9 of histone $\mathrm{H} 3$, interacts with the HP1 and could recruit SUV39H HMTase leading to methylate nearby histone. This molecular mechanism spreads the heterochromatin state. Lysine 4 is the most lovable methylation site on Histone H3 promoting activation effect through 2 mechanisms-

A. The binding to the $\mathrm{H} 3$ tail is inhibited by NuRD chromatin remodelling and histone deacetylase complex leading to the repressive effect.

B.The methylation of histone $\mathrm{H} 3 \mathrm{~K} 4$ provides a barrier in methylation of lysine 9 could be repressive.

These 2 repressive events provide a net activating effect.H3K4 is basically trimethylated and usually associated with the 5'end of an active transcriptional initiation. Trimethylation of lysine 36 of histone H3 (HK36Me3) is associated with the 3'end of an active gene. Thus, it is taken for transcriptional elongation. The various histone methylations like H3K4, H3K9, H3K79, H3R3 etc. The main function of $\mathrm{H} 3 \mathrm{~K} 4$ is gene activation while methylation at the $\mathrm{H} 3 \mathrm{~K} 9$ is chromatin condensation, required for DNA methylation. The methylation at the H3K79 promotes telomeric silencing while H4R3 promotes the chromatin assembling. The combinatorial code depicts how much to express or silence genes in a given nucleosome. The methylated lies in combination developed by single HMTasc called Ash 1, had two effects in drosophila showing positively. Primarily, these methylations stimulated the binding of an activator called Brahma and secondarily, binding of repressors like HP1, polycomb. Thus, normal inactivation of $\mathrm{H} 3 \mathrm{~K} 9$ is covered in the context 
of other two histone methylation. Perhaps, a cell could read in different chemical combinations of histone modification to promote its molecular effect.

\section{Common Examples of Epigenetic Diseases}

Epigenetic modifications lead to an altered phenotype which can either be a normal change or a full-fledged human disorder. Epimutations are responsible for a large number of human diseases.

Table 1 - Epigenetic Diseases, Symptoms and Causes

\begin{tabular}{|c|c|c|c|}
\hline Diseases & \begin{tabular}{l}
\multicolumn{2}{c}{ Catego } \\
ry of \\
Disease \\
\end{tabular} & Etiology & $\begin{array}{l}\text { Epigenetic } \\
\text { Proteins/Ge } \\
\text { nes } \\
\end{array}$ \\
\hline $\begin{array}{l}\text { Fragile } \mathrm{X} \\
\text { Syndrome } \\
\text { (Danielle } \\
\text { Simmons et al) }\end{array}$ & $\begin{array}{l}\text { Mental } \\
\text { disorder }\end{array}$ & $\begin{array}{l}\text { Expansion } \\
\text { and } \\
\text { methylation of } \\
\text { CGG repeat in } \\
\text { FMR1 } \\
\text { UTR, } \\
\text { promoter } \\
\text { methylation }\end{array}$ & FMR1 Gene \\
\hline $\begin{array}{l}\text { ATR-X } \\
\text { Syndrome } \\
\text { (Danielle } \\
\text { Simmons et al) }\end{array}$ & $\begin{array}{l}\text { Mental } \\
\text { Disorde } \\
\mathrm{r}\end{array}$ & $\begin{array}{l}\text { Mutations in } \\
\text { ATRX gene, } \\
\text { hypomethylati } \\
\text { on of certain } \\
\text { repeat and } \\
\text { satellite } \\
\text { sequences }\end{array}$ & ATRX Gene \\
\hline $\begin{array}{l}\text { Cervical } \\
\text { Cancer (Amr } \\
\text { M et al) }\end{array}$ & Cancer & HPV, & $\begin{array}{ll}\text { E6, } & \text { E7 } \\
\text { Proteins } & \end{array}$ \\
\hline $\begin{array}{l}\text { Hepatocarcino } \\
\text { ma (Amr M et } \\
\text { al) }\end{array}$ & Cancer & $\begin{array}{l}\mathrm{HCV} \\
\mathrm{HBV}\end{array}$ & $\begin{array}{l}\text { Core Protein } \\
\mathrm{HBx}\end{array}$ \\
\hline $\begin{array}{l}\text { Kaposi's } \\
\text { Sarcoma (Amr } \\
\text { M et al) }\end{array}$ & Cancer & KSHV & $\begin{array}{l}\text { LANA, RTA, } \\
\text { vFLIP, } \\
\text { vGPCR, vIL- } \\
6\end{array}$ \\
\hline $\begin{array}{l}\text { Merkel Cell } \\
\text { Carcinoma } \\
(\text { Amr M et al) }\end{array}$ & Cancer & $\mathrm{MCV}$ & $\mathrm{T}$ antigen \\
\hline $\begin{array}{l}\text { Angelman's } \\
\text { Syndrome } \\
\text { (Danielle } \\
\text { Simmons et al) }\end{array}$ & $\begin{array}{l}\text { Mental } \\
\text { Disorde } \\
\mathrm{r}\end{array}$ & $\begin{array}{l}\text { Deregulation } \\
\text { of one or } \\
\text { more } \\
\text { imprinted } \\
\text { genes } \\
\text { 15q11-13 at } \\
\text { (maternal) }\end{array}$ & UBE3A Gene \\
\hline $\begin{array}{l}\text { Rett Syndrome } \\
\text { (Danielle } \\
\text { Simmons et al) }\end{array}$ & $\begin{array}{l}\text { Mental } \\
\text { Disorde } \\
\mathrm{r}\end{array}$ & $\begin{array}{l}\text { Mutation } \\
\text { within } \\
\text { MECP2 gene } \\
\text { located on the } \\
X\end{array}$ & MECP2 Gene \\
\hline
\end{tabular}

\begin{tabular}{|c|c|c|c|}
\hline & & chromosome & \\
\hline $\begin{array}{l}\text { Prader-Willi } \\
\text { Syndrome } \\
\text { (Danielle } \\
\text { Simmons et al) }\end{array}$ & $\begin{array}{l}\text { Mental } \\
\text { Disorde } \\
\mathrm{r}\end{array}$ & $\begin{array}{l}\text { Deregulation } \\
\text { of one or } \\
\text { more } \\
\text { imprinted } \\
\text { genes } \\
15 q 11-13 \text { at } \\
\text { (paternal) } \\
\end{array}$ & OCA2 Gene \\
\hline $\begin{array}{l}\text { Coffin-Lowry } \\
\text { Syndrome } \\
\text { (Danielle } \\
\text { Simmons et al) }\end{array}$ & $\begin{array}{l}\text { Mental } \\
\text { Disorde } \\
\mathrm{r}\end{array}$ & $\begin{array}{l}\text { Mutation in } \\
\text { Rsk-2, histone } \\
\text { phosphorylati } \\
\text { on }\end{array}$ & $\begin{array}{l}\text { RPS6KA3 } \\
\text { Gene }\end{array}$ \\
\hline $\begin{array}{l}\text { ICF Syndrome } \\
\text { (Danielle } \\
\text { Simmons et al) }\end{array}$ & $\begin{array}{l}\text { Immune } \\
\text { Disorde } \\
\mathrm{r}\end{array}$ & $\begin{array}{l}\text { DNMT3b } \\
\text { mutations, } \\
\text { DNA } \\
\text { hypomethylati } \\
\text { on } \\
\end{array}$ & $\begin{array}{l}\text { DNMT3B, } \\
\text { ZBTB24 } \\
\text { Genes }\end{array}$ \\
\hline $\begin{array}{l}\text { Rubinstein- } \\
\text { Taybi } \\
\text { Syndrome } \\
\text { (Danielle } \\
\text { Simmons et al) }\end{array}$ & $\begin{array}{l}\text { Mental } \\
\text { Disorde } \\
\mathrm{r}\end{array}$ & $\begin{array}{l}\text { Mutation in } \\
\text { CREB- } \\
\text { binding } \\
\text { protein, } \\
\text { histone } \\
\text { acetylation }\end{array}$ & $\begin{array}{l}\text { CREBBP or } \\
\text { EP300 Gene }\end{array}$ \\
\hline $\begin{array}{l}\alpha- \\
\text { Thalassaemia } \\
\text { (Danielle } \\
\text { Simmons et al) }\end{array}$ & & $\begin{array}{l}\text { Methylation } \\
\text { of } \alpha \text { 2-globin } \\
\text { CpG island, } \\
\text { deletion of } \\
\text { HBA1 and } \\
\text { HBQ1 }\end{array}$ & $\begin{array}{l}1 \text { or more } \alpha- \\
\text { globin Genes }\end{array}$ \\
\hline
\end{tabular}

\section{INTRODUCTION TO HTLV-1}

\section{A. Structure and Classification -}

\section{A.1. Taxonomy/Classification}

Retroviruses can be classified depending on:

a. the morphology of thecore of the entire virus particle

b. the sequence homologies that becomes perceptible after phylogenetic analyses.

HTLV-1, a retrovirus, has infected 0.01-0.02billion people worldwide. Human T-lymphotropic virus type 1 (HTLV-1) belongs to Deltaretrovirus group (Matsuoka \& Jeang, 2007). HTLV-1 is reported to have six subtypes (A to F). The epidemiological status of the virus is not affected by HTLV1 subtypes as indicated by studies performed in varied disciplines. As per reports, no record has been found where pathogenicity of HTLV-1 has been affected or impacted by HTLV-1 subtyping. The major observation by the researchers working on this virus has been that the cosmopolitan subtype A causes a majority of infections.

\section{A.2. Virion structure}


HTLV-1 has an outer wrapping, envelope, that comes from the infected cells and is composed of glycoproteins. The viral genome contains two identical copies of ssRNA attached covalently to each other. The surface receptors of the host cells identify and communicate with the proteins present on the surface of the virus. This virus is termed a retrovirus because the viral mRNA is synthesised by the process of reverse transcription, wherein, reverse transcriptase is used for the formation of a complementary DNA molecule that was generated from an RNA template and which ultimately acts as the template for the synthesis of viral mRNA. The reverse transcriptase used in the generation of viral mRNA is complexed with the genome of the virus. Infected cellsproduce daughter cells in the host cells with integrated proviral DNA by the process of replication. These daughter cells continue to transcribe the proviral DNA and bud progeny virions. HTLV-1 infects CD4+ T-cells and as a result, causes lymphoma and leukemia. The only host cells that can provide their machineryto HTLV-1 for the production of progeny are Tlymphocytes even though it can invade a variety of cells, including B-cells, T-cells, and endothelial cells (Luciana\&Leandra et al).

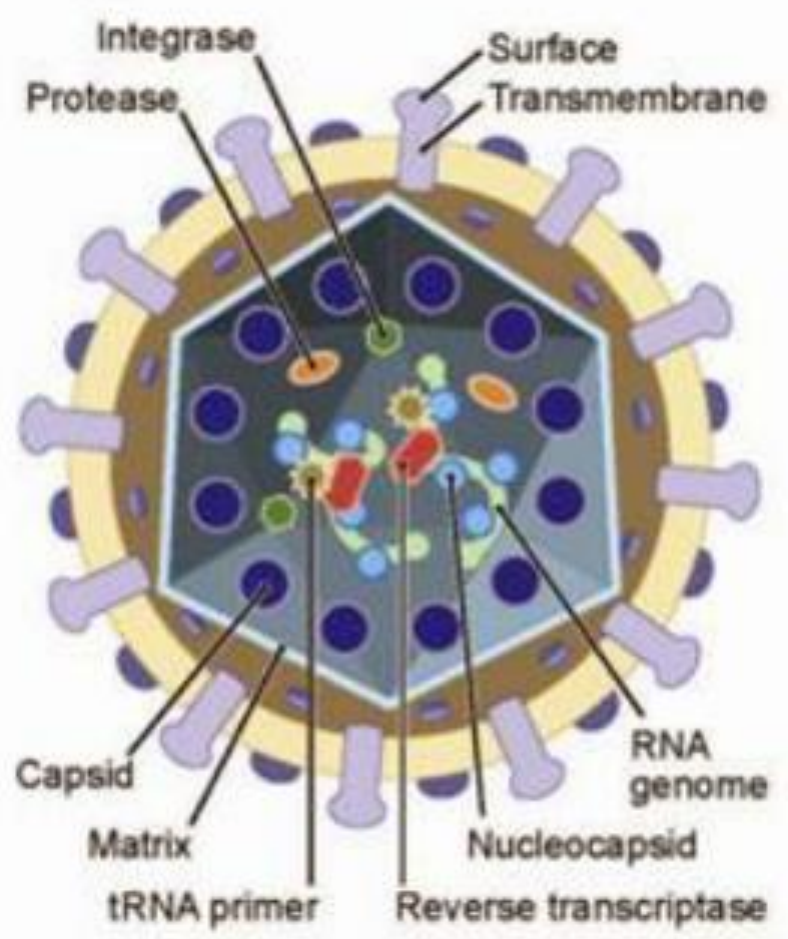

Fig. 1. Fully Developed Mature HTLV-1 Virion (Michael Lairmore et al, 2011)

\section{A.3. Structure of viral genome}

HTLV-1 contains a linear, dimeric, positive single stranded RNA genome of 8,507nucleotides, with a 5'-cap and a 3 'poly-A tail. There are two long terminal repeats (LTRs) of about 600nt long at the 5' and 3' ends that contain the U3, $\mathrm{R}$, and U5 regions. There is also a primer binding site (PBS) at the 5'end and a polypurine tract (PPT) at the 3'end. In addition to the essential viral genes gag, prt, pol, and env, HTLV-1 encodes regulatory (tax and rex) and accessory genes(p12, p13, p30 and HBZ) for the $\mathrm{pX}$ region open reading frames (ORFs), which are located between the env gene and the 3' portion of the viral genome(Kazumi\&Toshiki). This region contains at least four partially ORFs which encode accessory proteins (p12, $\mathrm{p} 13 / \mathrm{p} 30$ ), the Rex post-transcriptional regulator (ORF III) and the Tax protein (ORF IV). Tax activates transcription initiation from the viral promoter in the $\mathrm{U} 3$ region of the long terminal repeat, and Rex regulates viral gene expression post-transcriptionally by facilitating the cytoplasmic expression of the incompletely spliced viral mRNAs.
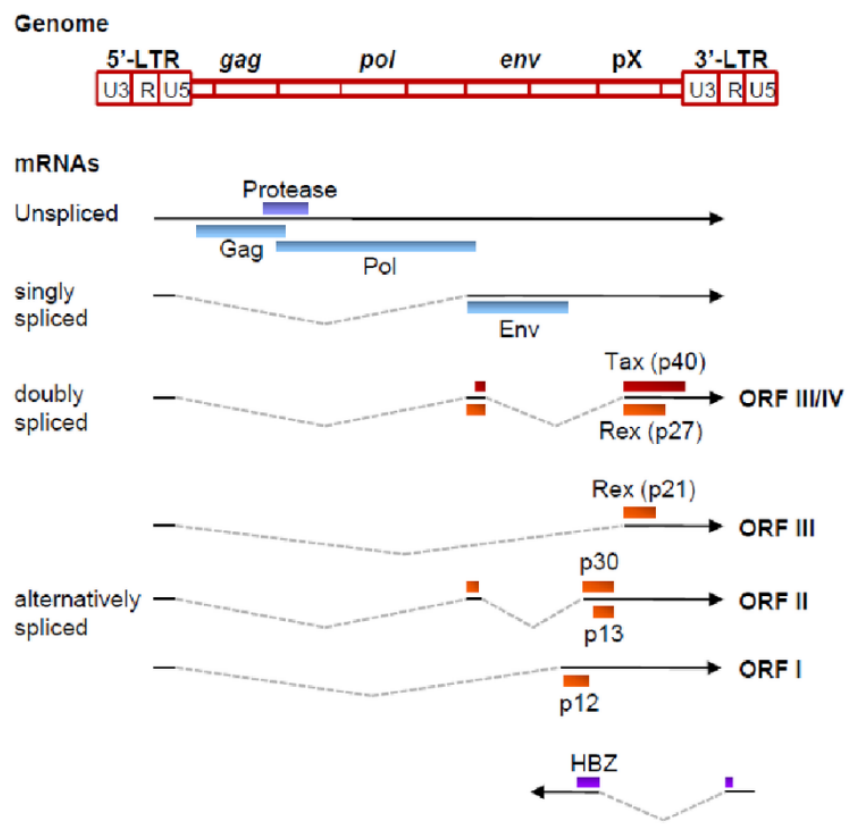

Fig. 2. Proviral Genome of HTLV-1 (Zhaoxia Qu and Gutian Xiao, 2011)

\section{$B$. Epidemiology of infection- Worldwide distribution -}

Human T cell lymphotropic virus type 1 is known to infect at least $0.01-0.02$ billion people around the globe. This blood borne virus is endemic in Central and West Africa, the Caribbean, East Asia, and Central and South America, and in intravenous drug users in the United States. Japan, 
majorly the southwest region, has the highest disease occurrence with HTLV-1 being the cause.

In Taiwan, Iran, and Fujian, the disease occurrence is 0.1$1 \%$. The incidence is about $1 \%$ in Papua New Guinea, the Solomon Islands, and Vanuatu, where the subtype $\mathrm{C}$ of HTLV-1 is the major causal organism. In Europe, HTLV-1 is rarely detected. However, the infection is prevalent in high-risk population in Europe. In America, the virus infects American Indians and African Americans. It is prevalent among IV drug users and one-tenth of HIV patients. The infection rate in the USA is around $1 \%$ in general.

HTLV-I prevalence in Australia is very high among the indigenous populationat about $10-45 \%$. HTLV-1 came to Australia 9000 years ago with Indonesian immigrants.

In a research, it was shown that up to $5 \%$ of people infected with the virus develop ATLL and symptoms appear over a period of 20-30 years.

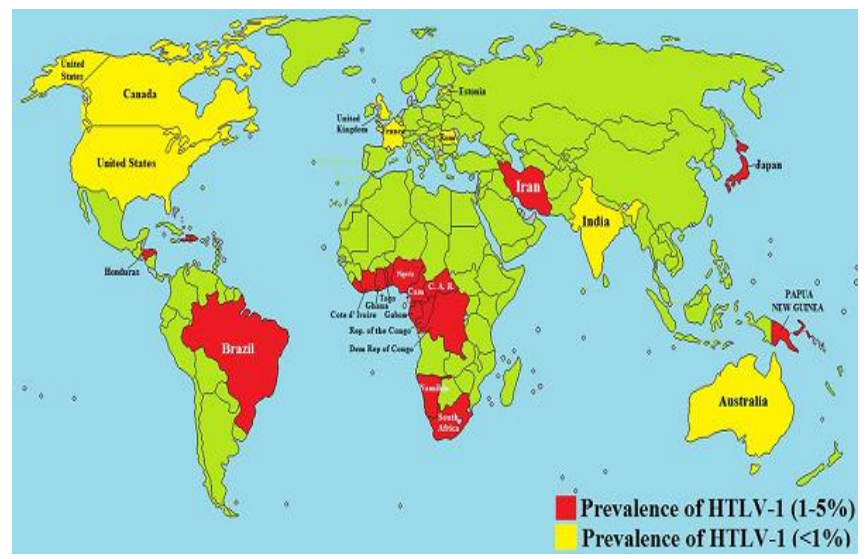

Fig. 3. Geographical Representation of Prevalence of HTLV-1 across the World (Mona Fani et al, 2018)

\section{Mode of Transmission -}

The HTLV-1 infection transmits majorly through three modes:

a. Vertical Transmission - from mother to baby immediately after or before parturition. Extended breastfeeding is the major factor leading to vertical transmission.

b. Sexual Transmission - unprotected intercourse with an infected spouse, multiple sexual partners during life, STD infections are the major risk factors.

c. Parenteral Transmission - blood transfusion of HIVinfected and the usage of injection that was used by an infected individual are the primary factors leading to parenteral transmission.

\section{C.1. Mother-to-child transmission}

Mother-to-child transmission can occur through the placenta, perinatally, or via breastfeeding. Transplacental and perinatal transmissions are a rarity, as indicated by various evidence. The major factor leading to mother-tochild transmission is prolonged breastfeeding(Toshinori\&Yukihito). The transmission is more likely by infected cells as virions minus host cells are rarely identified in human breast milk. Cells present in breast milk, namely, lymphocytes, macrophages, and mammary gland epithelial cells, may be predisposed to HTLV-1 infection. Palatal tonsils and intestines are believed to be possible sites of viral entry as lymphocytes, cells susceptible to HTLV-1, are present in abundance in these areas. The mechanism adopted by the virus for crossing the epithelial barrier is not completely understood yet. However, it is believed that human enterocytic cells might be more prone to HTLV-1 infection or to HTLV-1 virions crossing the epithelium and infecting dendritic cells through the transcytosis mechanism.

\section{C.2. Sexual transmission}

As far as sexual transmission of HTLV-1 is concerned, a few studies carried out on the gender that is most often infected by this virus suggest that transmission of HTLV-1 from male to female could play a more significant role and could be more efficient, especially in men with a history of penile sores or ulcers. The virus could be transmitted through damaged or infected mucosa, or transcytosis through epithelial cells. Sexual transmission requires entry through a mucosal barrier.(Edward L. Murphy et al).The semen, however, also contains some HTLV-1 infectious cells, such as CD4+ $\mathrm{T}$ cells, macrophages and dendritic cells, which may play a role in the sexual transmission through semen. With regard to female to male transmission, infected cells have been frequently found in cervical inflammatory secretions and cervical carcinoma in women infected with HTLV-1. In summary, there are very few studies in this area and several questions are still unanswered regarding the mechanisms of sexual transmission of HTLV-1. Any of the data obtained was extrapolated to HTLV-1 for the study of other retroviruses. However, not all this information can be faithfully extrapolated to HTLV and therefore, further investigations are needed to achieve more accurate data.

\section{C.3. Blood transmission}

Transfusion of whole blood or cellular blood products and needle sharing among intravenous drug users may cause blood transmission (EmilianaEusebio et al). It is not necessary to move through a mucosal barrier in the case of blood transmission, and infected cells will transmit the virus directly by cell-to-cell transmission or to dendritic cells through cell free transmission. Cell-to-cell transmission is 


\section{International Journal of Engineering Applied Sciences and Technology, 2020 \\ Vol. 5, Issue 8, ISSN No. 2455-2143, Pages 186-197 \\ Published Online December 2020 in IJEAST (http://www.ijeast.com)}

also the most efficient way to spread the virus by blood, as we have seen previously with other routes of transmission. A research comparing viral transmission following plasma transfusion from individuals with various human retroviruses found that seroconversion occurred in $89 \%$ of individuals who received plasma from individuals infected with HIV-1, but in none of those who received plasma from individuals infected with HTLV-1 or HTLV-2. The relationship of transmission with inflammation and malignancy is of concern. Several reports indicate that people who get HTLV-1 from the blood are more likely to develop inflammatory disorders, whereas people who get the virus during breastfeeding are more likely to develop $\mathrm{T}$ cell malignancies. In addition to certain factors that may alter this probability, such as age of infection, amount of virus, and immune response, this means that various cell populations may be affected by the mechanism of infection and may be a determinant in developing an inflammatory disease or cancer.

\section{Pathogenesis - Symptoms/Diseases Caused -}

\section{D.1. Viral structure and replication}

HTLV-1 is a complex human retrovirus that belongs to Delta retrovirus genus. Complex retroviruses, including lentiviruses such as HIV, have several proteins that require more complex transcriptional processing than the simple retroviruses. This viral genome is composed by the retroviral genes gag, pro, pol and env, which encode some viral structural proteins. The gag gene encodes the Matrix (MA), Capsid (CA) and Nucleocapsid (NC) proteins.

The pro gene encodes a viral protease that is responsible of facilitating the maturation of viral particles. The pol gene encodes Reverse Transcriptase (RT), RNaseH (RH) and Integrase (IN). Env gene encodes gp46 Surface Unit (SU) and gp21 Transmembrane Unit (TU). Additionally, it has the $\mathrm{pX}$ region, that contains the genes of six viral accessory proteins: Tax, Rex, p12I, p13II/p8, p30II and Basic Zipper Factor (HBZ) protein (EmilianaEusebio et al). HTLV-1 has two sense proviral genomic strands: a positive sense strand that encodes most of structural proteins, and a negative or antisense strand that encodes HBZ. HTLV-1 frames contain two flanking long terminal repeat (LTR) sequences with three components: a unique 3' (U3) region, a repeated (R) region, and a unique $5^{\prime}$ (U5) region.

HTLV-1 has mainly tropism for CD4+ cells, but can also infect CD8+ cells, B lymphocytes, dendritic cells, monocytes and endothelial cells. HTLV-1 has the ability of attachment and fusion to the target cells (EmilianaEusebio et al). The attachment begins when surface subunit (SU) of the HTLV-1 envelope glycoprotein (Env) interacts with three cellular surface receptors: Glucose Transporter (GLUT1)(Sanaz Ahmadi Ghezeldasht et al), Heparin Sulphate Proteoglycan (HSPG) and the VEGF-165 receptor
Neuropilin-1 (NRP-1). These receptors are widely distributed on target cells. Following attachment and fusion of the virus to the target cell, the viral RNA is delivered into the cytoplasm and is converted into double stranded DNA (dsDNA) through reverse transcription. Then dsDNA is integrated into the host nuclear genome. This provirus is transcribed by cellular RNA polymerase II. Subsequent post transcriptional regulation process is essential for splicing and transport of HTLV-1 mRNA. Then, the viral mRNA is exported from the nucleus to the cytoplasm. Viral proteins are translated and transported to the plasma membrane with two copies of genome RNA that at the virus budding site of the plasma membrane form a virus particle (Basyuk, E. et al) These budding particles are released from the cell surface, undergoing a maturation process by the action of viral proteases.

\section{D.2. Symptoms:}

Human T-cell leukaemia virus, type 1 (HTLV-1) generally causes no signs or symptoms. (Bangham, C. R et al )However,some affected people may later develop adult Tcell leukaemia (ATL), HTLV-1 associated myelopathy/tropical spastic paraparesis (HAM/TSP) or/andmedical conditions.

Approximately $2-5 \%$ of people with HTLV-1 will develop ATL, a cancer of the T-cells (a type of white blood cell). The signs and symptoms of this condition and the disease progression vary from person to person. Affected people may have the following features:

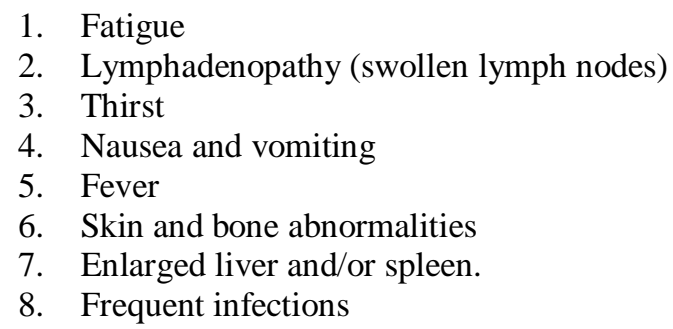

Roughly .25-2\% of people with HTLV-1 will develop HAM/TSP, a chronic, progressive disease of the nervous system. Signs and symptoms of this condition vary but may include:
1. Progressive weakness
2. Stiff muscles
3. Muscle spasms
4. Backache
5. 'Weak' bladder
6. Constipation

\section{D.3. Causes:}

Human T-cell leukaemia virus, type 1 (HTLV-1) occurs when a person is infected by the human $\mathrm{T}$-cell 


\section{International Journal of Engineering Applied Sciences and Technology, 2020 \\ Vol. 5, Issue 8, ISSN No. 2455-2143, Pages 186-197 \\ Published Online December 2020 in IJEAST (http://www.ijeast.com)}

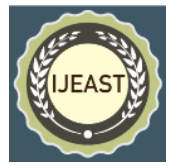

leukaemia retrovirus. HTLV-1 is spread by blood transfusions, sexual contact and sharing needles. It can also be spread from mother to child during birth or breastfeeding. It is unclear why some people with HTLV-1 develop adult T-cell leukaemia (ATL), HTLV-1 associated myelopathy/tropical spastic paraparesis (HAM/TSP) or other medical conditions, while others remain asymptomatic (show no signs or symptoms) their entire lives.( Akbarin, M. Et al ).

\section{E. Clinical Features/Diagnostic Methods -}

\section{E.1 Clinical features-}

ATL patients show a variety of clinical manifestations because of various complications of organinvolvement by ATL cells, opportunistic infections and/or hypercalcemia. These three oftencontribute to the extremely high mortality of the disease. Lymph node, liver, spleen and skin lesions arefrequently observed (Tsukasaki, K et al). Although less frequently, digestive tract, lungs, central nervous system, bone and/or other organs may be involved. Large nodules, plaques, ulcers, and erythrodermas are common skin lesions. Immune suppression is common. Approximately $26 \%$ of 854 patients with ATL had active infections at diagnosis in a prior nationwide study in Japan. The infections were bacterial in $43 \%$, fungal in $31 \%$, protozoal in $18 \%$, and viral in $8 \%$ of patients. Individuals with indolent ATL might have no manifestation of the disease and are identified only by health check-ups and laboratory examinations.

ATL cells, so called "flower cells", are usually detected easily in the blood of affected individuals except in smouldering type, which mainly has skin manifestations and lymphoma type. The histological analysis of aberrant cutaneous lesions or lymph nodes is essential for the diagnosis of thesmouldering type with mainly skin manifestations and lymphoma type of ATL, respectively. Because ATLcells in the skin and lymph node can vary in size from small to large and in form from pleomorphic toanaplastic and Hodgkin-like cell with no specific histological pattern of involvement, distinguishing the disease from Sezary syndrome, other peripheral T-cell lymphomas and Hodgkin lymphoma can at times be difficult without examinations for HTLV-1 serotype/genotype.

Hypercalcemia is the most distinctive laboratory abnormality in ATL as compared to other lymphoid malignancies and is observed in $31 \%$ of patients $(50 \%$ in acute type, $17 \%$ in lymphoma type and $0 \%$ in the other two types) at onset. Individuals with hypercalcemia do not usually have osteolyticbone lesions. Parathyroid hormonerelated protein or receptor activator of nuclear factor kappa B ligand(RANKL) produced by ATL cells is considered the main factor causing hypercalcemia.

\section{E.2. Diagnostic Methods-}

The diagnosis of typical ATL is not difficult and is based on clinical features, ATL cell morphology, mature helper-Tcell phenotype and anti-HTLV-1 antibody in most cases. Those rare cases which might be difficult to diagnose can be shown to have the monoclonal integration of HTLV-1 proviral DNA in the malignant cells as determined by Southern blotting. However, its sensitivity is around $5 \%$ of ATL cells among normal cells. Furthermore, the monoclonal integration of HTLV-1 is also detected in some HAM/TSP patients and HTLV-1 carriers. After the diagnosis of ATL, subtype-classification of the disease, reflecting prognostic factors, clinical features and natural history of the disease are based on the presence of organ involvement, leukemic manifestation and values for $\mathrm{LDH}$ and calciumis necessary for the selection of appropriate treatment.

Major prognostic indicators for ATL, elucidated among 854 patients with ATL in Japan by multivariate analysis were advanced performance status, high LDH level, age of 40 years or more, more than three involved lesions, and hypercalcemia. Additional factors associated with a poor prognosis include thrombocytopenia, eosinophilia, bone marrow involvement, a high interleukin (IL)-5serum-level, CC chemokine receptor 4 (CCR4) expressions, lung resistance-related protein (LRP), p53mutation and p16 deletion by multivariate analysis. Specific for the chronic type of ATL, high LDH, high blood urea nitrogen (BUN), and low albumin levels were identified as factors for a poor prognosis by multi-variate analysis [10]. Primary cutaneous tumoral type generally included among smouldering ATL had a poor prognosis in a uni-variate analysis.

Recently, a retrospective review of 807 patients in Japan led to a prognostic index for acute- and lymphoma-type ATL based on five prognostic factors: stage, performance status (PS), age, serum albumin and sIL2R. In the validation sample, the index was reproducible with median survival times(MSTs) of 3.6, 7.3, and 16.2 months for patients at high, intermediate, and low risk, respectively.

The Japan Clinical Oncology Group (JCOG)-Lymphoma Study Group (LSG) conducted a meta-analysis of three consecutive trials exclusively for aggressive ATL (Tsukasaki, K et al) (see below). OS analysis of a total 276 patients with acute-, lymphoma- or unfavourable chronicATL identified two significant prognostic factors, PS and hypercalcemia. In the validation sample, a proposed prognostic index using the two factors into two strata revealed MSTs of 6.3, and 17.8 months for patients at high and low risk, respectively. In both studies, however, the 5year OS rate was less than $15 \%$ even in the low-risk group, indicating that they are not sufficient to properly identify non-candidates for allo-HSCT which can achieve a cure of ATL despite considerable treatment-related mortality. 


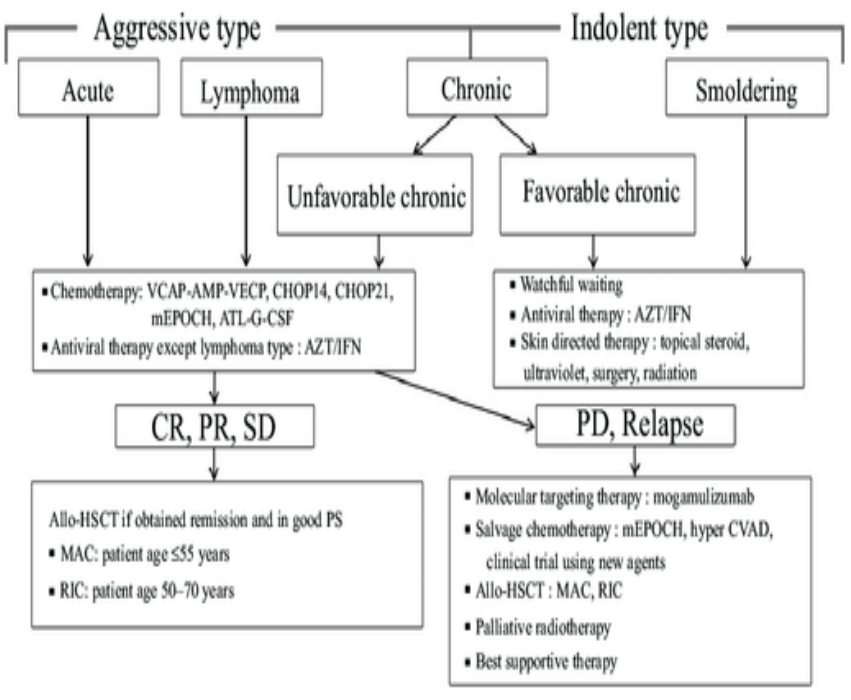

Fig. 4. Diagnosis of ATL and Therapeutic Strategies (Atae Utsunomiya et. Al., 2015)

\section{TREATMENT STRATEGIES AVAILABLE FOR THE DISEASES CAUSED BY HTLV-1 OTHER THAN METHYLATION}

HTLV1 leads to diseases like

1. ATLL (Adult T-cell Leukemia/Lymphoma) - a rare aggressive T-cell Lymphoma.

2.Spastic paraparesis (also called HTLV-1-associated myelopathy, HAM).

Here we will discuss about ATLL in which transformation and unregulated proliferations of T-cells takes place. $P^{53}$ isa Tumor Suppressor gene which regulates cells either by apoptosis or by cell cyclearrest.If there is DNA damage which cannot be repaired, then $P^{53}$ will degrade that cell by releasing NOXA and PUMA leads to apoptosis. $P^{53}$ regulates the cell by releasing $P^{21}$ which is inhibitor of CDK2 leads to G1 arrest and by releasing 14-3-3sigma which is inhibitor of CDK1 leads to G2 arrest. So, in the case of HTLV1, there is inhibition of Tumour suppressor gene $P^{53}$ In ATLL there are two oncoproteins, i.e. TAX and WIP1, these oncoproteins inhibit $P^{53}$ normal functioning by cascade of pathways leads to T-cell Transformation and unregulated proliferation.

Here are some drugs we will discuss which increases the survivability of patients by suppressing the effect of HTLV1: -

\section{Mogamulizumab-}

In this approach cells which express CCR4(CC chemokine receptor 4) are eliminated by means of antibody dependent cellular cytotoxic effect.

By this method antiviral load and inflammatory effect are reduced in cell culture. The anti-CCR4 antibody mogamulizumab selectively targets and reduce the number of HTLV-1 infected cells(Tomoosato et al). In ADCC(Antibody dependent cellular cytotoxicity) humanized monoclonal Antibodies are selectively target and binds to the Lymphocytic cells containing CCR4.Monoclonal Antibodies activates Natural Killer(NK) cells and monocytes that initiates the cytotoxic molecules, perforin and granzyme-b, that kills malignant T-Cell containing CCR4. In this approach the Monoclonal Ab. we are using are defucosylated in the sugar linked to Asparagine at 297 position in Fc region of Mogamulizumab leads to increase in binding affinity of Antibody towards affected cell which my increase the ADCC activity by 100 folds.

\section{Zidovudine(AZT) with Interferon alpha-}

AZT could act as antiviral agent. HTLV1 patients having spastic mylopathy (TSP/HAM) have intense cytotoxic TCell response against T-Lymphocytes that express Tax protein and eliminate such cells. Enhancement of Cytotoxic T-cell response against HTLV1 Lymphocytes was done by combining of AZT and IFN- $\alpha$ in those patients whose CTL response was poor. (E.Matutes et al). The plasma level of VEGF becomes high in ATL patients leads to expression of NF-kB. The effect of combination of AZTand Interferon- $\alpha$ is to reduction in the plasma level of VEGF leads to antiangeogenesis (GhadaKchour et al). AZT \& IFN- $\alpha$ does not have exceptionally good response against HTLV-1 so in combination with AZT \& IFN- $\alpha$, arsenic trioxide is also added. AZT \& IFN- $\alpha$ induces subduing of intracellular tax protein expression.IFN- $\alpha$ alone induce mild repression of cell propagation. Combination of AZT \& IFN- $\alpha$ shows intense suppression of growth than IFN- $\alpha$ alone (Shuichi Kinpara et al). IFN- $\alpha$ alone induce cell cycle arrest i.e Go/G1 arrest because IFN- $\alpha$ enhances $\mathrm{p} 21$ expression which is CDK-2 Inhibitor. Combination of AZT \& IFN- $\alpha$ enhance apoptotic cell fraction by expression of BAX (pro-apoptotic factor) in ILT (Interleukin-2 dependent HTLV-1 infected Tcells.

\section{Lamivudine (3TC)-Cytosine Nucleoside Reverse Transcriptase Inhibitor}

In this approach, 2',3'dideoxycytidine, a cytosine analogue is used to inhibit Viral DNA Replication of HTLV-1 in THcells. Lamivudine is less potent than AZT in the suppression the proliferation of HTLV-1 infected cells. The 


\section{International Journal of Engineering Applied Sciences and Technology, 2020 \\ Vol. 5, Issue 8, ISSN No. 2455-2143, Pages 186-197 \\ Published Online December 2020 in IJEAST (http://www.ijeast.com)}

immunotoxicity of this drug is very low which is beneficial for patients. (EmannelaBalesterieri et al ). Rapid fall in Viral DNA for patients during the treatment with Lamivudine suggests that the high pre-treatment viral DNA copy number maintained by active viral replication.

\section{NOVEL THERAPIES INVOLVED}

The traditional approaches for the treatment of ATL were based in the types of drugs and the radiation therapy that were available initially. A well-defined treatment algorithm is followed for treating ATL. In this algorithm, the technique of chemotherapy is combined sequentially with the intrathecal prophylaxis and granulocyte colony stimulating factor (G-CSF). However, there is a risk of mortality associated with such traditional approaches and this led to the development of novel therapeutic agents. Gradually, several clinical trials were conducted with major focus on novel therapeutic agents. Yet a full proof effective treatment for HTLV 1 has not been discovered. Some of the novel agents in the question include purine analogs, brentuximab, nivolumab, alemtuzumab, vedotin, and inhibitors like EZH1/2 dual inhibitor and histone deacetylase inhibitors. (Katsuya H, et al., 2017).

\section{Nucleoside Analogs -}

As the name suggests, the purine analogs are purine molecules that are structurally similar to the normal purine bases present in the Deoxyribose Nucleic Acid (DNA) strand. These analogs function in a competitive manner to replace the normal bases in DNA. This further leads to the impairment in the cell cycle. Nucleoside analogs consist of both purine analogs and pyrimidine analogs. Some of the nucleoside analogs are as follows: -

a) Pentostatin (deoxycoformycin) - It is a form ofpurine analog and can be used alone or in combination with other agents or treatment methods. Hence it is the most extensively used purine analog. (Tsukasaki K, Tobinai K, 2013). Pentostatin can be isolated from actinomycetesStreptomyces antibioticus or Aspergillusnidulans (Spiers, A S., 1996, Robak, T., \&Robak, P., 2012,). It is found effective in treating cutaneous T-cell lymphomas, prolymphocyticleukaemia, chronic lymphocytic leukaemia, non-Hodgkin's lymphomas and adult Tcell lymphoma-leukaemia. (Spiers, A S., 1996).

Mode of action- It acts as an analog of adenine and inhibits the activity of adenosine deaminase (ADA). ADAplays a vital role in the purine metabolism in the cell. Deficiency of ADA can lead to severe combined immunodeficiency (SCID) in children (Spiers, A S., 1996). Pentostatin induces double stranded breaks in DNA thereby resulting in cell cycle arrest (Robak, T., \&Robak, P., 2012).

b) Cladribine- Formed by a simple reaction involving substitution of chlorine with hydrogen atom at It is synthesized (Robak, T., \&Robak, P., 2012,). Approved by the European Union, Japan, and USA to be used in the standard treatment of some lymphoid malignancies and hairy cell leukaemia (Tsukasaki K, Tobinai K, 2013, Hermine, O, 2018). It shows resistance to the deamination process carried out by ADA.

Mode of action- The cytotoxic effects of Cladribine are seen in cells present in both growing phase and resting or quiescent phase. The cytoxicity is caused either by inhibiting the enzymes like DNA polymerases or the processes like DNA repair mechanism. In some cases, breaks in the DNA strands are also induced due to the phosphorylated cladribine. The DNA thus damaged eventually leads to apoptosis or necrosis (Robak, T., \&Robak, P., 2012, Hermine, O, 2018).

c) Fludarabine - unlike cladribine, fludarabine is used as a standard molecule for treating B-cell chronic lymphocytic leukaemia (CLL). (Tsukasaki K, Tobinai K, 2013, Hermine, O, 2018). It is commercially available in its prodrug form called as fludarabine 5'-monophosphate (FAMP). The prodrug is converted to its active form rapidly once administered intravenously.

Mode of action- Fludarabine is a purine analog and gets converted to Fludarabine triphosphate in the cell. This activated metabolite causes cytotoxicity. Fludarabine is responsible for blocking the translocation of necrosis factor kappa B. As mentioned in other analogs, the eventually it leads to cell apoptosis (Robak, T., \&Robak, P., 2012).

d) 2'-Deoxy-2'- $\beta$-fluoro-4'-azidocytidine (FNC)-The FNC was reported as an effective pyrimidine analog in the treatment of Hepatitis C. Similar inhibitory effects were observed when such analogs were employed in the case of cell lines infected with HTLV-1. Moreover it also inhibits the growth of the Hepatitis B virus (HBV) of humans and duck HBV also. FNC can also inhibit the synthesis of the Tax protein that is required primarily for the transcription and transformation of the virus. (Wang J. and Wang X. et al, 2013).

Mode of action- FNC can be acted upon by the kinase to form FNC triphosphate. This FNC 


\section{International Journal of Engineering Applied Sciences and Technology, 2020 \\ Vol. 5, Issue 8, ISSN No. 2455-2143, Pages 186-197 \\ Published Online December 2020 in IJEAST (http://www.ijeast.com)}

triphosphate lacks 3' hydroxyl group. Once incorporated into the viral parent DNA strand, it causes premature termination of newly formed DNA strand and thus replication of viral DNA is inhibited. This inhibition further leads to cell cycle arrest. In an independent study, FNC was found to induce S1 and G0 phases in the host cell cycle along with inhibiting the viral DNA replication. (Wang J. and Wang X. et al, 2013).

\section{Brentuximabvedotin (BV) -}

BV is one of the chimeric antibodies for humans synthesized from CD30, a member of tumor necrosis factor responsible for cell proliferation (HirooKatsuya, Kenji Ishitsuka, 2017). BV is approved and found effective in treating $\mathrm{CD}^{+} 0^{+} \mathrm{CTCL}$, Hodgkin lymphoma (HL) and CD $30^{+}$PTCL. It is under phase 2 of the pilot clinical study for the treatment of HTLV 1. (Hermine, O, 2018, El Hajj et al., 2020).

Mode of action- Since BV is an anti- CD30 monoclonal antibody attached to monomethyl auristatin E (MMAE), it forms an antibody drug conjugate (ADC). The MMAE is highly toxic molecule that is responsible for disrupting the microtubules of the cell. When this ADC is bound to the CD30 expressing cells, it forms the ADC- CD30 complex. This complex is internalized in the cell followed by the proteolytic cleavage of MMAE. Once MMAE is released, it disrupts the microtubules leading to cell death (Hermine, $\mathrm{O}$, 2018, El Hajj et al., 2020).

\section{Bortezomib -}

It is a well proteasome inhibitor that is approved by the European Medicines Agency (EMA) and USA. It is found effective in the treatment of mantle cell lymphoma (Hermine, O, 2018). When in the case of ATL, it is still under clinical trials being conducted in Japan. (Tsukasaki K, Tobinai K, 2013).

Mode of action- Bortezomib possesses inhibitory activity against $26 \mathrm{~S}$ proteasome complex. It functions by degrading I $\mathrm{B}-\alpha$ and preventing the transcription and translocation of necrosis factor $\mathrm{NF}-\mathrm{\kappa B}$ in the cells. As a result, a signal pathway is induced leading to necrosis or cell death (Hermine, O, 2018, A. Soltani et al., 2019,). Further it enhances the sensitivity of cancerous cells to the treatment methods followed earlier (Hermine, O, 2018).

\section{CONCLUSION}

Epigenetics, now a days has redefined our views of genetics, with rationale relevance for popular perceptions of genetic determinism, heredity and also tried to provide different frame shift in perspective of every disease especially "the dreaded cancer". Many aspects of the field are of interest to non-academic audiences Direct-to-consumer DNA methylation tests for biological age [the 'epigenetic clock'] and male infertility have also started appearing on the market. Unveiling epigenetic and genetic changes involved in cancer pathogenesis has always been a strenuous task. Epigenome profile defines a set of cellular identities, cellcell interactions driving tumorigenesis. There is still an urgent need to translate the findings to the clinical research, where they could be used for diagnostic, prognostic, and treatment response evaluation for cancer.

\section{REFERENCE}

1. Waterland, R. A., \& Michels, K. B. (2007). Epigenetic epidemiology of the developmental origins hypothesis. Annu. Rev. Nutr., 27, 363-388.

2. Inbar-Feigenberg, M., Choufani, S., Butcher, D. T., Roifman, M., \& Weksberg, R. (2013). Basic concepts of epigenetics. Fertility and sterility, 99(3), 607-615.

3. Mazzio, E. A., \& Soliman, K. F. (2012). Basic concepts of epigenetics: impact of environmental signals on gene expression. Epigenetics, 7(2), 119130.

4. Reik, W., Dean, W., \& Walter, J. (2001). Epigenetic reprogramming in mammalian development. Science, 293(5532), 1089-1093.

5. Wyrick, J. J., \& Parra, M. A. (2009). The role of histone $\mathrm{H} 2 \mathrm{~A}$ and $\mathrm{H} 2 \mathrm{~B}$ post-translational modifications in transcription: a genomic perspective. Biochimica et Biophysica Acta (BBA)-Gene Regulatory Mechanisms, 1789(1), 37-44.

6. Braunschweig, U., Hogan, G. J., Pagie, L., \& Van Steensel, B. (2009). Histone H1 binding is inhibited by histone variant H3. 3. The EMBO journal, 28(23), 3635-3645.

7. Sanchez, R., \& Zhou, M. M. (2009). The role of human bromodomains in chromatin biology and gene transcription. Current opinion in drug discovery \& development, 12(5), 659.

8. Jones, P. A., \& Takai, D. (2001). The role of DNA methylation in mammalian epigenetics. Science, 293(5532), 1068-1070.

9. Ren, J., Singh, B. N., Huang, Q., Li, Z., Gao, Y., Mishra, P., .. \& Jiang, S. W. (2011). DNA hypermethylation as a chemotherapy target. Cellular signalling, 23(7), 1082-1093.

10. Harikrishnan, K. N., Chow, M. Z., Baker, E. K., Pal, S., Bassal, S., Brasacchio, D., ... \& El-Osta, A. (2005). Brahma links the SWI/SNF chromatin-remodeling complex with MeCP2-dependent transcriptional silencing. Nature genetics, 37(3), 254-264. 


\section{International Journal of Engineering Applied Sciences and Technology, 2020 \\ Vol. 5, Issue 8, ISSN No. 2455-2143, Pages 186-197 \\ Published Online December 2020 in IJEAST (http://www.ijeast.com)}

11. Rice, J. C., \& Allis, C. D. (2001). Histone methylation versus histone acetylation: new insights into epigenetic regulation. Current opinion in cell biology, 13(3), 263273.

12. Lund, A. H., \& van Lohuizen, M. (2004). Epigenetics and cancer. Genes \& development, 18(19), 2315-2335.

13. El-Araby, A. M., Fouad, A. A., Hanbal, A. M., Abdelwahab, S. M., Qassem, O. M., \& El-Araby, M. E. (2016). Epigenetic pathways of oncogenic viruses: therapeutic promises. Archiv der Pharmazie, 349(2), 73-90.

14. Danielle Simmons, (2008), Epigenetic Influences and Diseases, Nature Education 1(1):6

15. Matsuoka, M., \& Jeang, K. T. (2007). Human T-cell leukaemia virus type 1 (HTLV-1) infectivity and cellular transformation. Nature Reviews Cancer, 7(4), 270-280.

16. Barros, L. R. C., Linhares-Lacerda, L., MoreiraRamos, K., Ribeiro-Alves, M., Motta, M. C. M., BouHabib, D. C., \& Savino, W. (2017). HTLV-1-infected thymic epithelial cells convey the virus to CD4+ T lymphocytes. Immunobiology, 222(12), 1053-1063.

17. Nakano, K., \& Watanabe, T. (2012). HTLV-1 Rex: the courier of viral messages making use of the host vehicle. Frontiers in microbiology, 3, 330.

18. Fujino, T., \& Nagata, Y. (2000). HTLV-I transmission from mother to child. Journal of reproductive immunology, 47(2), 197-206.

19. Murphy, E. L., Figueroa, J. P., Gibbs, W. N., Brathwaite, A., Holding-Cobham, M., Waters, D., ... \& Blattner, W. A. (1989). Sexual transmission of human T-lymphotropic virus type I (HTLV-I). Annals of internal medicine, 111(7), 555-560.

20. Eusebio-Ponce, E., Anguita, E., Paulino-Ramirez, R., \& Candel, F. J. (2019). HTLV-1 infection: An emerging risk. Pathogenesis, epidemiology, diagnosis and associated diseases. Revista Española de Quimioterapia, 32(6), 485.

21. Ghezeldasht, S. A., Shirdel, A., Assarehzadegan, M. A., Hassannia, T., Rahimi, H., Miri, R., \& Rezaee, S. R. (2013). Human $T$ lymphotropic virus type I (HTLV-I) oncogenesis: molecular aspects of virus and host interactions in pathogenesis of adult $\mathrm{T}$ cell leukemia/lymphoma (ATL). Iranian journal of basic medical sciences, 16(3), 179.

22. Basyuk, E., Galli, T., Mougel, M., Blanchard, J. M., Sitbon, M., \& Bertrand, E. (2003). Retroviral genomic RNAs are transported to the plasma membrane by endosomal vesicles. Developmental cell, 5(1), 161-174.

23. Bangham, C. R., Araujo, A., Yamano, Y., \& Taylor, G. P. (2015). HTLV-1-associated myelopathy/tropical spastic paraparesis. Nature Reviews Disease Primers, 1(1), 1-17.

24. Akbarin, M. M., Farhadi, S., Allahyari, A., Koshayar, M. M., Shirdel, A., Rahimi, H., ... \& Rafatpanah, H.
(2020). Interaction of perforin and granzyme B and HTLV-1 viral factors is associated with Adult T cell Leukemia development. Iranian Journal of Basic Medical Sciences, 23(8), 1007.

25. Tsukasaki, K., Marçais, A., Nasr, R., Kato, K., Fukuda, T., Hermine, O., \& Bazarbachi, A. (2020). Diagnostic approaches and established treatments for adult $\mathrm{t}$ cell leukemia lymphoma. Frontiers in Microbiology, 11, 1207.

26. El-Araby, A. M., Fouad, A. A., Hanbal, A. M., Abdelwahab, S. M., Qassem, O. M., \& El-Araby, M. E. (2016). Epigenetic pathways of oncogenic viruses: therapeutic promises. Archiv der Pharmazie, 349(2), 73-90.

27. Tsukasaki, K., Tobinai, K., Hotta, T., \& Shimoyama, M. (2012). Lymphoma study group of JCOG. Japanese journal of clinical oncology, 42(2), $85-95$

28. Sato, T., Coler-Reilly, A. L., Yagishita, N., Araya, N., Inoue, E., Furuta, R., ... \& Yamano, Y. (2018). Mogamulizumab (Anti-CCR4) in HTLV-1-associated myelopathy. New England Journal of Medicine, 378(6), 529-538.

29. Duvic, M., Evans, M., \& Wang, C. (2016). Mogamulizumab for the treatment of cutaneous T-cell lymphoma: recent advances and clinical potential. Therapeutic advances in hematology, 7(3), 171-174.

30. Matutes, E., Taylor, G. P., Cavenagh, J., Pagliuca, A., Bareford, D., Domingo, A., ... \& Reilly, J. T. (2001). Interferon $\alpha$ and zidovudine therapy in adult T-cell leukaemia lymphoma: response and outcome in 15 patients. British journal of haematology, 113(3), 779784.

31. Kchour, G., Makhoul, N. J., Mahmoudi, M., Kooshyar, M. M., Shirdel, A., Rastin, M., ... \& Bazarbachi, A. (2007). Zidovudine and interferon- $\alpha$ treatment induces a high response rate and reduces HTLV-1 proviral load and VEGF plasma levels in patients with adult T-cell leukemia from North East Iran. Leukemia \& lymphoma, 48(2), 330-336.

32. Kinpara, S., Kijiyama, M., Takamori, A., Hasegawa, A., Sasada, A., Masuda, T., ... \& Kannagi, M. (2013). Interferon- $\alpha \quad($ IFN- $\alpha)$ suppresses HTLV-1 gene expression and cell cycling, while IFN- $\alpha$ combined with zidovudin induces p53 signaling and apoptosis in HTLV-1-infected cells. Retrovirology, 10(1), 1-15.

33. Balestrieri, E., Forte, G., Matteucci, C., Mastino, A., \& Macchi, B. (2002). Effect of lamivudine on transmission of human T-cell lymphotropic virus type 1 to adult peripheral blood mononuclear cells in vitro. Antimicrobial agents and chemotherapy, 46(9), 3080-3083.

34. Taylor, G. P., Hall, S. E., Navarrete, S., Michie, C. A., Davis, R., Witkover, A. D., ... \& Weber, J. N. (1999). 
Effect of lamivudine on human T-cell leukemia virus type 1 (HTLV-1) DNA copy number, T-cell phenotype, and anti-tax cytotoxic T-cell frequency in patients with HTLV-1-associated myelopathy. Journal of virology, 73(12), 10289-10295.

35. Katsuya, H., \& Ishitsuka, K. (2017). Treatment advances and prognosis for patients with adult T-cell leukemia-lymphoma. Journal of clinical and experimental hematopathology, 17008.

36. Robak, T., \& Robak, P. (2012). Purine nucleoside analogs in the treatment of rarer chronic lymphoid leukemias. Current pharmaceutical design,18(23), 3373-3388.

37. Wang, J., Wang, X., Gao, C., Song, X., Niu, Z., Gao, Z., ... \& Wang, H. (2013). The pyrimidine analog FNC inhibits cell proliferation and viral protein synthesis in HTLV-1-infected cells. Molecular medicine reports, 7(5), 1656-1660.

38. Spiers, A. S. (1996). Deoxycoformycin (pentostatin): clinical pharmacology, role in the chemotherapy of cancer, and use in other diseases. Haematologia, 27(2), 55.

39. Tsukasaki, K., \& Tobinai, K. (2013). Biology and treatment of HTLV-1 associated T-cell lymphomas. Best Practice \& Research Clinical Haematology, 26(1), 3-14.

40. Hermine, O., Ramos, J. C., \& Tobinai, K. (2018). A review of new findings in adult $\mathrm{T}$-cell leukemialymphoma: a focus on current and emerging treatment strategies. Advances in therapy, 35(2), 135-152.

41. El Hajj, H., Tsukasaki, K., Cheminant, M., Bazarbachi, A., Watanabe, T., \& Hermine, O. (2020). Novel treatments of adult $\mathrm{T}$ cell leukemia lymphoma. Frontiers in microbiology, 11.

42. Lairmore, Michael et al (2011). Molecular Determinants of Human T-lymphotropic Virus Type 1 Transmission and Spread, Viruses, 3, 1131-1165.

43. Qu Zhaoxia, and Xiao Gutian (2011).Human T-Cell Lymphotropic Virus: A Model of NF- $\kappa \mathrm{B}-$ Associated Tumorigenesis, Viruses, 3, 714-749.

44. Fani, M, Rezayi, M, Meshkat, Z, et al (2018). Current approaches for detection of human T-lymphotropic virus Type 1: A systematic review. J Cell Physiol. ; 234: 12433-

12441. https://doi.org/10.1002/jcp.28087

45. Utsunomiya, Atae, Choi, Ilseung, Chihara, Dai, Seto, Masao (2015), Recent advances in the treatment of adult T-cell leukemia-lymphomas, Cancer Science, 10.1111/cas.12617. 